\title{
Dados, vícios e concorrência: repensando o jogo das economias digitais
}

RAFAEL A. F. ZANATTA I e RICARDO ABRAMOVAY ${ }^{I I}$

\section{Introdução}

A INVASÃO da privacidade não é um acidente, uma falha, uma consequência lateral indesejada ou uma distorção do funcionamento dos dispositivos digitais em rede que formam nossa vida cotidiana (Zuckerman, 2018). Ela é a essência do modelo de negócios dos gigantes digitais (Shapiro; Aneja, 2019). Quem lê estas linhas certamente já se preocupou em ampliar sua proteção, instalando aplicativos que evitam o fornecimento de certas informações ligadas a seus celulares ou até evitando certos temas em dispositivos de redes sociais (Tufekci, 2018). Apesar de sua nobreza de intenções, esse esforço até aqui tem sido praticamente inútil.

Muito mais que celulares ou computadores, é o conjunto da vida social contemporânea que se encontra, de forma massiva, ampla e permanente, sob escrutínio (Alter, 2017). O barateamento das câmeras de vídeo (Arthur, 2017) e sua instalação pervasiva nos centros urbanos de quase todo o mundo (Hartzog; Selinger, 2019), a digitalização dos automóveis (Hanvey, 2019), a ampliação do alcance da internet das coisas aos mais triviais objetos da vida cotidiana - da geladeira aos tênis de corrida, dos brinquedos infantis às escovas de dentes (Zuboff, 2019) -, o uso cada vez mais frequente do reconhecimento facial automático pelas polícias (Morris, 2019) tudo isso transforma o cotidiano dos cidadãos num vasto processo de produção de informações sobre as mais diferentes dimensões de suas atividades.

É verdade que obter informações sobre as opiniões, as atividades e as preferências das pessoas marca a vida das sociedades contemporâneas ao menos desde meados do século XIX. Como argumentou Michel Foucault, o surgimento da estatística e do controle populacional é um dos componentes da "governamentalidade" (governmentality) de matriz liberal (Curtis, 2002). Essas informações são necessárias tanto ao funcionamento de diferentes órgãos dos Estados como para a comercialização de produtos. Na atual "economia da atenção" (Wu, 2016), no entanto, atrair a atenção das pessoas é condição decisiva para que elas façam escolhas convenientes aos anunciantes. E essa atração apoia-se não só no esforço de conhecer o potencial comprador para oferecer-lhe o que virtualmente lhe interessa, mas também no empenho de prender sua atenção ao 
máximo e orquestrar seus impulsos. Há algo de peculiar nas "tecnologias aditivas" (Alter, 2017) de hoje.

A partir da segunda década do milênio, esse conhecimento adquiriu profundidade e amplitude inéditas, o que foi expresso de forma lapidar por Mark Zuckerberg, fundador do Facebook, rede social com mais de dois bilhões de usuários:

[...] com base no que as pessoas clicam, quais páginas curtem e outros sinais, criamos categorias - por exemplo, pessoas que gostam de páginas sobre jardinagem e vivem na Espanha - e então cobramos de anunciantes para mostrar anúncios para esse grupo de pessoas. Embora propaganda para grupos específicos exista muito antes de a internet existir, a publicidade online permite um direcionamento muito mais preciso e, assim, anúncios mais relevantes. (Zuckerberg, 2019)

O sucesso dessa publicidade de precisão depende de dispositivos que passam a fazer parte do cotidiano das pessoas e que, com muita frequência, elas carregam em seus corpos (Hartzog, 2018; Weiss, 2019). As informações sobre os comportamentos e as preferências das pessoas não dependem mais de pesquisas de opinião ou de sua expressão mercantil naquilo que elas efetivamente compram. Os dispositivos digitais produzem uma tal quantidade de dados que permitem que se antecipem as escolhas das pessoas e, por aí, que se ampliem as possibilidade de exercer influência sobre essas escolhas. Reportagem do New rork Times mostra que a localização e os deslocamentos das pessoas são rastreados por inúmeros aplicativos contidos em seus celulares, sem que elas o saibam, e comercializados por empresas especializadas em promover produtos e serviços com base no conhecimento que os movimentos dos indivíduos propicia (Valentino-DeVries et al., 2018).

Esse rastreamento constante das pessoas pode ser feito até mesmo sem GPS, por meio do cruzamento de dados sobre redes Wi-Fi, antenas de celular e distorções de frequências magnéticas registradas por smartphones. Por meio de "beacons" - um dispositivo minúsculo que emite sinais por meio de tecnologia bluetooth low energy - dentro das lojas, aplicativos dotados de códigos integrados com Software Development Kit (SDK) captam a localização precisa de uma pessoa indoor e enviam informações de geolocalização para os servidores de empresas especializadas em location-based advertising (Kwet, 2019). Com uma população dependente de seus próprios smartphones, carregando-os a todo o momento, garante-se uma quantidade massiva de dados. ${ }^{1}$

As mais importantes empresas do mundo contemporâneo são chamadas por Tim Wu (2016) de “mercadores de atenção”. São empresas “cujo negócio consiste em influenciar a consciência e que podem e vão radicalmente moldar como nossas vidas são vividas”. O que está em jogo, mostra Wu, não é apenas a economia ou a cultura deste ou daquele país e sim a própria natureza da vida social contemporânea. $\mathrm{O}$ modelo de negócios dos gigantes digitais e a troca da 
gratuidade dos serviços que oferecem por informações a nosso respeito abrem caminho a um grau de influência sobre nossas escolhas que questiona valores básicos da democracia, a começar por nossa autonomia (Frischmann; Selinger, 2018).

Uma das consequências culturais mais importantes dos rumos tomados pela revolução digital a partir da segunda década do milênio é o surgimento de uma nova disciplina no interior da filosofia, a ética de dados (Floridi; Taddeo, 2016). O tema torna-se essencial porque a natureza massiva e individualizada da coleta de dados está na base da vanguarda da inovação tecnológica atual: os três premiados em março de 2019 com o Prêmio Turing (uma espécie de prêmio Nobel da computação) trabalham sobre redes neurais que são "um sistema matemático complexo que pode aprender tarefas específicas analisando vasto montante de dados" (Metz, 2019).

É esse vínculo orgânico entre a vanguarda da inovação tecnológica contemporânea e a potencial corrosão de valores fundamentais da vida democrática que está fazendo da privacidade o tema mais importante da defesa dos direitos humanos mundo afora. Como sustenta Luciano Floridi (2013), esse direito à privacidade não pode ser visto dentro dos moldes clássicos de garantia de uma imunidade contra a intrusão da vida privada, como sustentou Louis Brandeis em 1890. Também não pode ser vista como capacidade de controlar os fluxos de dados produzidos por um indivíduo, como sustentou Alan Westin em 1968. A privacidade hoje está mais ligada ao coletivo e às proteções sociais contra inferências e discriminações abusivas. Nesse sentido, está mais próxima de um sistema de governança dos fluxos de dados e às ideias de "proteção de dados pessoais" formuladas na Europa, centradas em conceitos como dignidade e autodeterminação informativa (Rodotà, 2018). ${ }^{2}$ Essa group privacy, enfim, seria o "direito à imunidade de alterações desconhecidas, indesejadas ou não intencionais na sua própria identidade como uma entidade informativa, tanto ativa quanto passivamente" (Floridi, 2016).

Floridi tem argumentado que nossa abordagem ética é muito antropocêntrica (limitada a pessoas naturais) e atomística (o que conta é o indivíduo singular), sendo necessário reconceitualizar uma ética informacional a partir dos fluxos informacionais e uma análise detalhada dos elementos morais em torno da "gestão justa de um recurso informacional", a moralidade dos "produtos informacionais" gerados a partir dos sujeitos sociais, e a integridade dos "ambientes informacionais", culminando em uma "macroética" centrada na infoesfera (Floridi, 2013, p.13-53).

A defesa da privacidade e da proteção de dados pessoais ${ }^{3}$ envolve uma tensão essencial: exatamente por sua contribuição às mais importantes inovações tecnológicas contemporâneas, as informações coletadas pelos dispositivos digitais que compõem nosso cotidiano devem ser consideradas como um bem comum cuja utilização tem imenso potencial de melhorar a vida humana, quer se 
trate da gestão urbana, da saúde, da mobilidade, da luta contra o desmatamento ou da segurança pública. Cédric Villani (2018), prêmio Fields de matemática e hoje deputado na França, usa para caracterizá-lo a expressão "data commons". Por outro lado, porém, como mostra o relatório que Villani escreveu a pedido do presidente Macron, essa riqueza coletiva tem servido fundamentalmente a fortalecer o poder dos gigantes digitais. As bases de dados gigantescas controladas por essas empresas são usadas como training data para algoritmos de aprendizado por máquinas e I.A.

O mundo contemporâneo está ainda tateando na forma de lidar com essa tensão. Este texto aborda dois aspectos atuais das tensões em torno da economia da atenção, cujo domínio é exercido por gigantes como Alphabet (Google), Alibaba, Amazon, Apple, Microsoft, Facebook e Twitter. O primeiro refere-se ao problema dos vícios digitais, ou seja, a nossa dependência cada vez maior de dispositivos e aplicações sobre cujo desenho e cujos objetivos as pessoas não têm qualquer controle. Aqui está em debate o problema dos limites éticos da indução à compulsão (Schulson, 2018) e os efeitos prejudiciais das aplicações de internet, tanto em termos de acentuação da "polarização em grupo" (Sunstein, 2018 ) quanto do efeito macro de degradação da dignidade humana em razão de micro escolhas "racionais" de consumo (Frischmann; Selinger, 2018). O segundo refere-se ao problema anticoncorrencial da economia da atenção, em especial as condutas unilaterais abusivas relacionadas à influência sobre as escolha dos consumidores, as capacidades de "orquestração econômica" (Ezrachi; Stucke, 2016) e o problema fundamental da concentração econômica dessas empresas, o que tem mobilizado, como será explicado adiante, uma agenda neobrandeisiana no direito antitruste, com o retorno de discussões sobre intervenções estruturais (Facebook, WhatsApp e Instagram deveriam ser controladas pelo mesmo grupo?) e uma conexão explícita entre concorrência e democracia.

Nosso argumento é que esses dois eixos de tensão possuem um alto potencial de mobilização institucional nos próximos anos, dando ensejo a reformas regulatórias significativas. Ao mesmo tempo, eles abrem a possibilidade de pesquisas interdisciplinares nas ciências sociais.

\section{O problema dos vícios digitais}

A era digital transformou radicalmente o sentido da célebre tirada de Freud sobre a tríplice decepção da humanidade: a geológica, quando se descobre com Copérnico e Galileu que não estamos mais no centro do Universo; a biológica que faz de nós, com Darwin, descendentes de macacos; e a que deu origem à psicanálise, em que o inconsciente não permite mais que sejamos "os mestres em nossa própria casa". Num texto de 1919, "A inquietante estranheza", Freud mostra que somos permanentemente acompanhados de um duplo, de uma espécie de outro com o qual mantemos diálogos internos e que muitas vezes nos surpreende e até nos assusta. O psicanalista e antropólogo francês Frank Enjolras, relê “A Inquietante Estranheza” e observa que os dados extra- 
ídos de nossos posts, de nossos likes, de nossos movimentos, de nossas fotos e de nossas compras permitem que os algoritmos nos conheçam a ponto de saber não só o que fizemos e fazemos, mas sobretudo o que faremos. $\mathrm{O}$ "mestre na nossa própria casa", o inconsciente se revela não na sessão de psicanálise, na relação vivida entre dois seres humanos, de forma íntima, discreta e com a finalidade de ampliar nosso autoconhecimento, mas por dispositivos controlados por estruturas que coletam, armazenam e analisam nossos mais elementares gestos cotidianos e que dão concretude à ideia, hoje já banal, de que os algoritmos nos conhecem melhor que nós mesmos ou que as pessoas com quem convivemos em laços estreitos.

Esse heteroconhecimento, essa criptopredição apoia-se em técnicas que, é claro, em nada se assemelham às da psicanálise. $\mathrm{O}$ mais importante inspirador dos mecanismos em que se apoiam os vícios digitais contemporâneos é um psicólogo que não poderia estar mais distante da psicanálise: B. F. Skinner, o psicólogo de Harvard que, a partir dos anos 1930, levou adiante um conjunto de experiências com pombos e ratos, mostrando que o conhecimento e a interferência em comportamentos animais passam não pelo esforço de compreender seus sentimentos e sensações, e sim pelo estudo de estímulos, recompensas e punições determinantes do que fazem. Um de seus exemplos mais célebres é aquele em que, ao mobilizar um mecanismo, um pombo obtém um alimento. Ao fazê-lo novamente, o alimento não vem e a frustração se repete até que, de forma aleatória, o pombo recebe o alimento, e assim por diante. Por vezes, leva 50 segundos para o pombo obter alimento novamente, mas esse tempo pode ser cinco vezes maior ou menor. Um dos animais analisados por Skinner pressionou o mecanismo duas vezes e meia por segundo durante dezesseis horas seguidas (Schulson, 2018).

Skinner acreditava na possibilidade de, sob esse modelo, conhecer os comportamentos humanos para adequá-los a uma ordem social desejada. Os fundamentos filosóficos de seu trabalho revelam-se bem no título de uma obra dos anos 1970, Para além da liberdade e da dignidade. Para Skinner (2000), como bem mostra Shoshana Zuboff (2019), a liberdade humana não passa de ilusão e exprime nada mais que nossa ignorância sobre os mecanismos determinantes de nossas ações. Essas bases filosóficas e os progressos da psicologia no estudo da subjetividade, e não só dos comportamentos humanos, ajudam a explicar a perda de prestígio do comportamentalismo skinneriano nas ciências humanas, sobretudo a partir do final dos anos 1960 (Chomsky, 1971).

Mas os computadores e a conexão em rede transformaram esse quadro. $\mathrm{O}$ comportamentalismo ganhou novo alento tanto em prestigiosas organizações acadêmicas como para os governos e o meio empresarial. Em 1998, o psicólogo B. J. Fogg publica um artigo que marca a fundação de uma disciplina hoje largamente ensinada no "Laboratório de Persuasão Tecnológica" da Universidade Stanford. A disciplina é um acrônimo de "Computers as Persuasive Technologies" e ao mesmo tempo uma síntese de seu objetivo maior: Captology. Trata-se 
de estudar as técnicas por meio das quais os dispositivos digitais podem reter a atenção das pessoas. A captologia propõe desenhos comportamentais que se incrustam nos sistemas operacionais dos dispositivos que utilizamos em nosso dia a dia. Como mostra Shoshana Zuboff, o Google foi pioneiro na aplicação da disciplina. Seus engenheiros, lá por 2002, descobriram que os dados gerados pelas buscas dos usuários poderiam servir a prever seus comportamentos numa profundidade e numa escala inéditas. O próprio Gmail promove a conexão da identidade das pessoas com seus comportamentos e preferências. Da mesma forma, o Google Maps rastreia localização e movimentos.

Não se trata aqui de traçar o histórico da evolução dos diferentes dispositivos que respondem pelo fato de que, por exemplo, no Brasil, entre os mais jovens (de 16 a 24 anos), 40\% ficam mais de cinco horas por dia em conexão, segundo a pesquisa brasileira de mídia (Secretaria Especial de Comunicação da Presidência da República, 2016). Nos Estados Unidos, 42\% dos menores de 8 anos já possuem seus próprios aparatos digitais. Em 2011, eles eram apenas 1\% (Howard, 2017). Não é sem razão que a Associação Americana de Pediatria publicou em 2016 recomendações severas de restrição de smartphones para crianças, produzindo um guia de "dieta midiática" para famílias. ${ }^{4}$ Vai no mesmo sentido o título de recente matéria do Financial Times: "Why quitting smartphones is the new quitting smoking" [Por que largar os smartphones é o novo parar de fumar]. A reportagem mostra diversas iniciativas (algumas de natureza clínica) para reduzir a dependência das pessoas em consultar permanentemente seus celulares (Kuchler, 2018)

Pesquisa recente sobre vícios ligados a smartphones mostra, confirmando a predição de Skinner em sua experiência com os pombos, que o usuário médio de smartphone nos Estados Unidos checa seu dispositivo 63 vezes por dia e essa quantidade vem aumentando ano a ano. Oitenta e cinco por cento (85\%) das pessoas checam seus telefones enquanto estão conversando com amigos e familiares. Sessenta e nove por cento $(69 \%)$ dos usuários checam seus celulares em até cinco minutos depois que acordam (antes mesmo de espreguiçar e escovar os dentes!), e $87 \%$ fazem-no logo antes de dormir. Cinquenta e oito por cento $(58 \%)$ dos usuários tentaram mudar seus hábitos, mas apenas $41 \%$ dessas tentativas foram bem-sucedidas. ${ }^{5}$

Se for levado em conta apenas o uso do Google e do Facebook (ou seja, sem considerar outros aplicativos, nem tampouco os dados que vêm das geladeiras inteligentes e dos robôs domésticos, dos quais a Amazon já vendeu mais de cem milhões de unidades), o montante de dados coletados, armazenados e analisados é estonteante. Robert Shapiro e Sidharta Aneja, como parte de sua pesquisa sobre o uso de informações pessoais pelos gigantes digitais, obtiveram os dados que o Google e o Facebook dispunham de cada um deles, Shapiro, um "baby boomer" que usa bem menos as redes sociais que Aneja, um millenial. O Google dispunha de 3,5l gigabytes de dados de Aneja e o Facebook, 631 me- 
gabytes. Um megabyte de informação corresponde a 583 páginas de um documento em Word. Só do millenial Sidharta Aneja o Google possuía informações que, reunidas, perfaziam mais de dois milhões de páginas de um documento word (Shapiro; Aneja, 2019).

O importante, como bem mostra o psicólogo Adam Alter (2017), é que essa capacidade de reter a atenção das pessoas deriva de um verdadeiro vício promovido comercialmente e cultivado a partir de métodos que se apoiam no trabalho especializado de inúmeros especialistas. Na verdade, a própria noção de vícios digitais é nova:

[...] por décadas, os neurocientistas acreditavam que só drogas ou álcool poderiam conduzir a vícios [...] mas pesquisas recentes mostraram que o comportamentos viciantes produzem as mesmas respostas cerebrais do abuso de drogas [...] $\mathrm{Na}$ maior parte do tempo, o cérebro libera apenas uma pequena dose de dopamina, mas algumas substâncias e experiências viciantes exacerbam a produção de dopamina. (Alter, 2017, p.71)

E, da mesma forma que no vício químico, o cérebro vai produzindo cada vez menos dopamina, o que exige que a substância seja introduzida por meio da droga ou por meio da intensificação do comportamento viciante. "Em vez de produzir a saudável medida de dopamina que inspirava otimismo e alegria em resposta a pequenos prazeres, essas regiões adormecem até que sejam sobre estimuladas novamente".

Jogos eletrônicos levaram os vícios digitais a um nível explosivo. O aumento em seu uso, a partir do início do milênio, foi estimulado por duas inovações fundamentais: o acesso por meio do smartphone e a interação social online. Os resultados são estarrecedores. Em 2017 a indústria norte-americana de videogames faturou US\$ 36 bilhões, $18 \%$ a mais que em 2016 , quando o faturamento já tinha aumentado $20 \%$ com relação a 2015, segundo a Entertainement Software Association. Setenta e cinco por cento (75\%) do faturamento da Apple App Store vem de jogos. World of Warcraft, por exemplo, é jogado por mais de cem milhões de pessoas. Se fosse um país, os jogadores de Warcraft teriam a $20^{\text {a }}$ população mundial. Quarenta por cento (40\%) dos praticantes são viciados (Alter, 2017). Como a interação social em torno desses jogos é global, seus participantes comprometem com imensa frequência suas noites de sono para manter-se em conexão. Não é por outra razão que a Organização Mundial da Saúde (OMS) incluiu, em 2018, "gaming disorder" na classificação internacional de doenças. ${ }^{6}$

Adam Alter, ao explicar o problema das tecnologias aditivas, mostra que os indivíduos, sozinhos, são incapazes de resistir aos vícios digitais e às centenas de técnicas e engenharias projetadas para capturar a atenção e "prender a pessoa" dentro de uma aplicação, seja ela Instagram, seja Tinder, seja Facebook. Para Alter (2017), “a adição comportamental ainda está em sua infância e há uma boa chance de que ainda estejamos na linha de base, bem abaixo do pico". Com a chegada de dispositivos de realidade virtual e realidade expandida, abre-se a 
possibilidade de imersões mais profundas do que as proporcionadas por "stories" e fotos no Instagram.

O que haveria de alternativa regulatória para o problema dos vícios digitais? Além das opções de autorregulação (Schulson, 2018) - a criação de ferramentas de contenção de vícios pelas próprias empresas (e.g. lembretes sobre o tempo em que se fica conectado a uma aplicação específica ou mecanismos de desligamentos operados pelos usuários) -, Alter defende uma abordagem sociotécnica pautada por uma "engenharia cuidadosa". Para além das noções tradicionais de privacy by design ou de security by design (ou seja, privacidade e segurança da informação concebidas na fase de protótipo), Alter defende uma espécie de non addiction by design, ou seja, um cuidado, da parte dos engenheiros e programadores, com relação aos efeitos de adição de suas criações técnicas. ${ }^{7}$ Trata-se de um movimento contrário ao que há de tendência na "gamificação", ou seja, no uso de artefatos e processos artificiais de estímulo à permanência de uma pessoa na mesma atividade ou tarefa. Nesse sentido, Alter aproxima-se de uma longa tradição de estudos regulatórios dedicados à arquitetura e aos códigos, como os trabalhos de Lawrence Lessig (1999) sobre o modo como códigos regulam o comportamento humano, e os trabalhos da filósofa Mireille Hildebrandt (2008) sobre a necessidade de o direito ser reorientado à arquitetura e aos processos de criação de códigos e estruturas sociotécnicas.

Para além da autorregulação e da "engenharia cuidadosa" advogada por Alter, a professora de engenharia Elaine Ou, da Universidade de Sydney, propôs em sua coluna na Bloomberg uma saída mais audaciosa: tratar empresas como Facebook como "empresas de tabaco" e "empresas de bebida alcoólica".

O ponto de partida de Elaine Ou é o ensaio It's Time do Break Up Facebook, escrito pelo cofundador da empresa Chris Hughes, em maio de 2019. No texto, Hughes relata sua própria incapacidade de parar de "rolar a tela do Instagram" enquanto está brincando com seu filho. Para Ou (2019), o relato de Hughes não é isolado. Pesquisas conduzidas pela Royal Society for Public Health têm mostrado que as redes sociais podem causar efeitos positivos e negativos. Ao mesmo tempo que estimulam expressão e construção da identidade, geram ansiedade, privação de sono e um fenômeno chamado Fear of Missing Out (a ideia de que, se a pessoa não checar as atualizações no Twitter ou as novas publicações no Facebook, estará perdendo algo importante). Elaine Ou (2019), no entanto, nega as conclusões de Chris Hughes. Para ela, não se trata de "quebrar o monopólio" dessas poucas empresas por meio do direito antitruste, mas de "reduzir nossa dependência na indústria como um todo". Para a autora, o problema não está em apenas uma empresa, e sim nesse novo tipo de indústria que se dedica, nos dizeres de Evgeny Morozov (2018), a escavar nossas emoções e usar nossas relações sociais como matéria-prima.

Para Elaine Ou (2019), há duas opções institucionais para uma espécie de regulação de saúde pública para os vícios digitais. Primeiro, uma abordagem 
focada em rotulagem, ou seja, na obrigação de que o conteúdo do produto seja explicado e apresentado, com especial enfoque na publicidade sobre os riscos. Segundo, uma abordagem focada em inspeção sanitária, de modo a garantir a redução da assimetria entre consumidores e manufatura. Essa abordagem é mais complexa e difícil de operacionalizar, pois, diferentemente de um restaurante, os insumos e os produtos das empresas de tecnologia são imateriais (Quintarelli, 2019), o que exigiria "abrir os códigos" e permitir uma inspeção sobre os riscos à saúde pública.

Ainda há poucas propostas regulatórias que buscam atacar o problema dos vícios digitais nos Estados Unidos. Até o momento, dois projetos de lei possuem conexão com o tema, mas estão longe de avançar a ideia de Elaine Ou. O primeiro projeto, chamado "Do Not Track Act", foi proposto em 2019 pelo jovem senador Republicano Josh Hawley, e prevê a criação de um sistema de penalidades para empresas que não interromperem a coleta de dados após uma sinalização, via browser, de "do not track", em um sistema organizado pela Federal Trade Commission (FTC). Na apresentação do projeto de lei, Hawley argumentou que o projeto busca frear essa "economia do vício", na qual dados pessoais são massivamente coletados para prender as pessoas dentro das plataformas e aplicações.

O segundo projeto, chamado "The Data Care Act", foi proposto no final de 2018 por quinze senadores democratas. O projeto é a cristalização da proposta do Prof. Jack Balkin $(2015 ; 2017)$, de Yale, de um sistema de "fiduciários de informação", no qual as empresas de tecnologia teriam obrigações especiais de lealdade e honestidade com relação ao modo como os dados são usados. Balkin reconhece que, em razão da dependência das pessoas com relação aos serviços prestados pelas grandes empresas de tecnologia, devem-se abandonar os modelos puramente baseados em consentimento, substituindo-os por um sistema no qual o fiduciário da informação - tal como contadores, médicos e advogados - possui um dever de lealdade de não utilizar os dados dos consumidores em detrimento deles (Balkin, 2015). Lina Khan e David Pozen (2019), em artigo sobre o conceito de "fiduciários de informação", criticam a aplicação prática desse modelo, considerando que diversas empresas de tecnologia estão registradas em Delaware, onde há um "dever de lealdade" com os acionistas e com a maximização de bem-estar de investidores, o que levaria a uma tensão inescapável entre os interesses a serem tutelados.

O problema dos vícios digitais, em resumo, apresenta nova fronteira ao campo de políticas públicas e abre ampla discussão sobre alternativas regulatórias, longe de qualquer solução simples no curto prazo. Em termos éticos, o problema dos vícios conecta-se com três grandes discussões: primeiro, a natureza ética do design e de inovações tecnológicas desenhadas para hackear nossas vulnerabilidades e intensificar uma cultura narcísica e autoexploratória (Han, 2018); segundo, a discussão sobre qualidade de vida e a antiga reflexão, já fei- 
ta por Albert Borgmann, sobre como somos dominados pelas tecnologias de forma imperceptível, sucumbindo ao "paradigma do dispositivo" (Borgmann, 1987); terceiro, pela conexão intrínseca entre coleta de dados pessoais e técnicas de "engajamento" e personalizações que nos fazem mais dependentes de smartphones e suas aplicações, reforçando a importância regulatória da Lei Geral de Proteção de Dados Pessoais a partir de 2020 no Brasil. ${ }^{8}$

\section{O problema anticoncorrencial: estruturas e condutas}

A base de funcionamento da economia de mercado é a opacidade, ou seja, a ignorância em que se encontra cada ator econômico com relação ao que os outros vão fazer. Friedrich Hayek, prêmio Nobel de Economia e talvez o mais importante pensador liberal do século XX, sustenta, em texto hoje clássico, que ninguém (indivíduos, empresas ou Estado) possui de forma concentrada e sintética as informações que permitem saber onde é mais conveniente, tanto do ponto de vista privado como do social, alocar os recursos escassos dos quais a vida econômica se compõe. Numa sociedade descentralizada essas informações estão radicalmente distribuídas entre os protagonistas da vida econômica. Por isso, qualquer esforço de planejamento econômico estaria fadado ao fracasso, já que não há como concentrar esse conhecimento sob qualquer forma. Mas se é assim, como a sociedade produz e distribui os meios necessários a sua reprodução? A resposta de Hayek (1945) é que "num sistema em que o conhecimento dos fatos relevantes está disperso entre muitas pessoas, os preços podem agir para coordenar as diferentes ações de diferentes pessoas no mesmo sentido em que os valores subjetivos ajudam o indivíduo a coordenar as partes de seu plano".

Um dos maiores paradoxos de nosso tempo é que a revolução digital abriu caminho para modificar radicalmente a função informativa do sistema de preços na economia contemporânea (Abramovay, 2018). Afinal, com poder computacional crescente, dispositivos em mãos dos indivíduos e funcionamento em rede, as informações deveriam fluir cada vez melhor. Ampliam-se as oportunidades de venda do produto de um agricultor, se ele conhece os preços praticados nacionalmente e internacionalmente e não conta apenas com a informação que lhe é transmitida pelo comerciante local. Essa abundância de informação deveria reduzir os custos daquilo que George Stigler (1961), prêmio Nobel de Economia, chamou de "busca" ( search) do preço mais favorável, seja para o comprador, seja para o vendedor. Em princípio, o acesso dos participantes do mercado às informações que norteiam seus comportamentos deveria ser mais rápido, menos custoso e depender menos de intermediários. O mais importante é que esses atributos deveriam ampliar a participação nas melhores oportunidades de mercado. Yochai Benkler (2006), em A riqueza das redes, publicado em 2006, sustenta que a economia da informação em rede propicia a "emergência de um ambiente informacional em que os indivíduos são livres para assumir um papel mais ativo do que era possível na economia industrial da informação do século XX”. Essa visão edificante dos impactos das novas tecnologias da informação 
não só sobre o funcionamento dos mercados, mas sobre a democracia (por meio da formação de uma esfera pública operando rede) era compartilhada até o final da primeira década do milênio pela esmagadora maioria dos estudiosos do tema.

O paradoxo é que poucos anos após a publicação do livro de Benkler, a revolução digital acabou por converter-se no mais importante vetor de concentração de riqueza e de poder da história do capitalismo. O que está em jogo não é apenas o poder de mercado dos gigantes digitais contemporâneos, mas a formação de um sistema econômico apoiado inteiramente na coleta, na armazenagem e na análise de dados pessoais. O que, em tese, destinava-se a fortalecer um sistema informativo descentralizado e capaz de aprimorar o funcionamento do mercado, transformou-se num conjunto de dispositivos pelos quais alguns poucos atores econômicos conseguem conhecer de antemão (e não como resultado do funcionamento dos preços) as preferências e, por aí, a antecipar quais serão as escolhas do consumidor. Como mostra o livro fundamental de Ariel Ezrachi e Maurice Stucke (2016):

[...] a concorrência, tal como a conhecemos - a mão invisível que distribui as necessidades da vida - está sendo deslocada em muitos setores pela mão digitalizada. Esta última, mais que uma força natural, é fabricada pelo homem e, como tal, sujeita a manipulação.

$\mathrm{Na}$ visão hayekiana, por maior que seja o esforço das empresas em conhecer as preferências dos compradores, só o mercado é capaz de validar esse conhecimento. E essa validação é necessariamente ex-post. O grande leilão social que conduz à formação dos preços consagra-se, na célebre expressão de Léon Walras, num tateamento (tâtonnement), num sistema de experimentação e erro próprio à natureza dispersa da informação. Mas a capacidade de reunir dados e conhecer as preferências das pessoas muda esse quadro. E essa mudança passa a ameaçar a própria concorrência, uma vez que, longe de estar amplamente distribuída, a informação agora concentra-se nos atores que dela dispõem. Como essa massa de informações alimenta os algoritmos que permitem a aprendizagem automatizada capaz de detectar as preferências dos consumidores antes mesmo que eles façam suas escolhas, isso dá lugar à formação de um novo poder econômico, que Maurice Stucke (2018) não hesita em chamar de dadopólio.

Os dados que alimentam o modelo de negócios dominante na economia contemporânea não vêm apenas das plataformas operadas diretamente pelos gigantes digitais. O relatório do Conselho Presidencial de Conselheiros em Ciência e Tecnologia dos Estados Unidos mostra que embora empresas especializadas sempre tenham coletado informações para melhor conhecer os consumidores, agora, além da massa de informações coletadas no uso de redes sociais, ocorre uma "fusão de dados" (data fusion), que é quando "dados de diferentes fontes são colocados em contato daí emergindo novos fatos". Cada um desses dados isoladamente pode ser inofensivo do ponto de vista do respeito à privacidade do indivíduo. Mas sua reunião permite o estabelecimento de perfis e de formas de 
rastreamento das pessoas que vão muito além do que elas sabem e possivelmente do que elas permitiriam.

Mesmo que haja alguma dispersão nos dados coletados por diferentes plataformas (não só as dos gigantes digitais, mas nas compras, no uso de automóveis, nos cartões magnéticos que dão acesso a infraestruturas públicas como metrô e ônibus, entre outros), somente os atores que possuem massas gigantescas de informações são capazes de desenvolver a capacidade analítica de estabelecer as conexões necessárias para que os dados façam sentido. Essa é uma das mais importantes causas do paradoxo que converteu uma tecnologia cujos potenciais estavam na descentralização, no aumento da informação compartilhada e, portanto, na ampliação das oportunidades de mercado exatamente no seu contrário: a base sobre a qual funciona o maior poder político, econômico e cultural das sociedades modernas.

A expressão economia de dados não quer dizer que a vida social se tenha desmaterializado ou se tornado puramente virtual (Quintarelli, 2019). O mais importante é que os dados abrem caminho a três traços inéditos do capitalismo contemporâneo. O primeiro é que os próprios objetos materiais convertem-se em formas de captar e transmitir dados. Isso vai do televisor doméstico que responde a comando de voz ao automóvel autônomo. Dang Wenshuan, dirigente da gigante digital chinesa Huawei, estima que nada menos que $70 \%$ do valor de um carro autônomo estão em sua tecnologia da informação e da comunicação. Isso significa que esse setor da economia global será cada vez mais dominado por empresas digitais e não pelos fabricantes convencionais de automóveis (Kinge et al., 2019). Esse é o cenário da Internet das Coisas, no qual o Brasil buscou identificar suas potencialidades por meio do "Plano Nacional de Internet das Coisas" entre os anos 2017 e 2018.9

O segundo traço inédito do capitalismo contemporâneo é a publicidade de precisão, ou seja, a capacidade de dirigir mensagens apoiadas no conhecimento do perfil exato dos consumidores a partir das informações que a "fusão de dados" permite obter (Wu, 2016; Zuckerberg, 2019), somada ao fato da comodificação da vida cotidiana e das ações individuais e relacionais que podem ser registradas como dados pessoais (Morozov, 2018; Zuboff, 2019). O terceiro e mais importante é a capacidade de antecipar os comportamentos dos cidadãos e planejar as atividades econômicas a partir daí. Enquanto o varejo muda seus preços, em média entre um e três meses - o tempo necessário para que o sistema de preços sinalize aos atores econômicos, de forma descentralizada, a situação da oferta e da procura dos bens e serviços -, a Amazon tem a capacidade de mudar os preços dos dois bilhões de produtos que oferece a cada quinze minutos. É o que permite que Ariel Ezrachi e Maurice Stucke denominem o "olho digital" capaz de antecipar as escolhas a serem feitas pelos consumidores de "visão divina".

Nos Estados Unidos, as autoridades de regulação da concorrência, até muito recentemente, fizeram vista grossa para a concentração de poder eco- 
nômico correlativa à aplicação de "Big Data", "Data Analytics" e Inteligência Artificial à massa de dados em mãos dos gigantes digitais. Muitos casos de Data-Driven Mergers, como a aquisição da DoubleClick pela Google ou a aquisição do WhatsApp pelo Facebook, não passaram por análise de ato de concentração pela autoridade antitruste ${ }^{10}$ - ou, se passaram, foram autorizadas sem nenhum tipo de restrição severa, em razão da tese dominante de existência de benefícios aos consumidores e de inexistência de um problema fundamental de infração à ordem econômica. No caso Google Double Click, consagrou-se a tese de que não haveria um problema concorrencial pelo fato de o Google adquirir bases de dados que "pudessem ser exploradas em violação à privacidade dos consumidores" (FTC, 2007). O que deveria pesar na decisão da autoridade concorrencial seria a existência de "danos concorrenciais", mensuráveis, por exemplo, pela evidência de "eliminação potencial de competição em um mercado relevante" (FTC, 2007).

Nos últimos anos tem ocorrido um intenso debate, inclusive no Brasil, sobre a viabilidade de manutenção das lentes clássicas de análise antitruste e o problema das aquisições centradas em dados (Bagnoli, 2016; Fidelis, 2017; Krein, 2018; ). O Quadro 1 contrasta esse cenário com a expansão das fusões e aquisições de empresas de tecnologia, o que evidencia a estratégia agressiva dessas companhias de diversificar seu portfolio de atuação. Juntas, Alphabet, Facebook, Microsoft, Amazon e Apple foram responsáveis por mais de 450 aquisições.

Essa passividade se explica pelo ritmo das inovações tecnológicas e pelas novidades que esse ritmo trazia ao horizonte intelectual de decisões dessas autoridades, como a dificuldade de definir o "mercado relevante" dessas empresas de tecnologia e a dificuldade de definição da importância econômica dos dados pessoais para essas aquisições, considerando a ausência de critérios claros de classificação dos diferentes tipos de dados e o fato de que os dados também são utilizados como "pagamento" por uma aplicação "gratuita" de internet. ${ }^{11}$

No entanto, a dificuldade se apoia, sobretudo, na ideia de que só há prejuízo à concorrência caso a concentração econômica provoque aumento dos preços ao consumidor. Nesse referencial teórico clássico, típico da Escola de Chicago de Antitruste capitaneada por Robert Bork na década de 1970, o efeito anticompetitivo deve ser demonstrado por meio de testes empíricos e modelos matemáticos que podem comprovar uma relação de detrimento para o consumidor em um mercado específico. 
Quadro l - Visão geral dos "gigantes digitais" segundo CrunchBase

\begin{tabular}{|c|c|c|c|c|c|}
\hline $\begin{array}{l}\text { Grupo } \\
\text { econômico }\end{array}$ & $\begin{array}{l}\text { Receita } \\
\text { anual } \\
\text { estimada }\end{array}$ & Áreas de atuação & Patentes & Subsidiárias & $\begin{array}{l}\text { Aquisições } \\
\text { e exemplos }\end{array}$ \\
\hline $\begin{array}{l}\text { Alphabet } \\
\text { Inc. } \\
\text { (Google) }\end{array}$ & $\$ 136.8 \mathrm{~B}$ & $\begin{array}{l}\text { Biotecnologia, } \\
\text { plataforms de } \\
\text { blogging, e-mail, } \\
\text { mecanismos de } \\
\text { busca, software, } \\
\text { streaming de vídeo }\end{array}$ & 27.086 & $\begin{array}{l}\text { X (projetos } \\
\text { científicos), Verily } \\
\text { (dados de saúde), } \\
\text { Waymo (sensores } \\
\text { de transporte), Nest } \\
\text { Labs (automação } \\
\text { doméstica), } \\
\text { Chronicle, Loon } \\
\text { (conectividade), } \\
\text { GV (venture } \\
\text { capital), Sidewal } \\
\text { Labs (smart cities), } \\
\text { Calico (doenças e } \\
\text { envelhecimento) }\end{array}$ & $\begin{array}{l}234 \\
- \\
\text { Motorola } \\
\text { Mobility (\$12B, } \\
\text { 2012), Nest Labs } \\
\text { (\$3B, 2014), } \\
\text { DoubleClick } \\
(\$ 3,1 \mathrm{~B}, 2007), \\
\text { Looker }(\$ 2,6 \mathrm{~B}, \\
\text { 2019), YouTube } \\
(\$ 1,7 \mathrm{~B}, 2006), \\
\text { Waze }(\$ 1,1 \mathrm{~B}, \\
\text { 2013), HTC } \\
(\$ 1,1 \mathrm{~B}, 2013), \\
\text { AdMob }(\$ 750 \mathrm{M}, \\
\text { 2009), ITA } \\
\text { Software }(\$ 700 \mathrm{M}, \\
\text { 2011), DeepMind } \\
\text { (\$650M, 2014) }\end{array}$ \\
\hline Facebook & $\$ 58.9 \mathrm{~B}$ & $\begin{array}{l}\text { Mídia social, rede } \\
\text { social, apps para } \\
\text { cellular, mensageria, }\end{array}$ & 5.116 & $\begin{array}{l}\text { Wit.ai (inteligência } \\
\text { artificial, Oculus } \\
\text { (realidade virtual), } \\
\text { Messenger } \\
\text { (mensageria), } \\
\text { Instagram } \\
\text { (compartilhamento } \\
\text { de fotos) }\end{array}$ & $\begin{array}{l}77 \\
\text { - } \\
\text { WhatsApp (\$19B, } \\
\text { 2014), Oculus } \\
\text { VR (\$2B, 2014), } \\
\text { Instagram (\$1B, } \\
\text { 2012), LiveRail } \\
\text { (\$400M, 2014), } \\
\text { Face.com (\$100M, } \\
\text { 2012), Redkik } \\
\text { (\$100M, 2018), } \\
\text { Atlas Solutions } \\
\text { (\$100M, 2013) }\end{array}$ \\
\hline
\end{tabular}




\begin{tabular}{|c|c|c|c|c|c|}
\hline Amazon & $\$ 232.9 \mathrm{~B}$ & $\begin{array}{l}\text { Desenvolvimento de } \\
\text { negócios, entregas, } \\
\text { e-commerce, vendas } \\
\text { online, SaaS, } \\
\text { software }\end{array}$ & 11.155 & $\begin{array}{l}\text { Dpreview (revisão } \\
\text { de câmeras), Whole } \\
\text { Foods Markets } \\
\text { (produtos orgânicos), } \\
\text { Woot (loja online), } \\
\text { IMDB (avaliações } \\
\text { de filmes), Alexa } \\
\text { Accelerator,A The } \\
\text { Book Depository } \\
\text { (loje online de } \\
\text { livros), Twitch } \\
\text { (plataforma para } \\
\text { gamers) }\end{array}$ & $\begin{array}{l}83 \\
- \\
\text { WholeFoods } \\
\text { (\$13B, 2017), } \\
\text { Goodreads (\$1B, } \\
\text { 2013), Zappos } \\
(\$ 1,2 \mathrm{~B}, 2009) \text {, } \\
\text { Twitch (\$970M, } \\
\text { 2014), BuyVIP } \\
\text { (\$100M, 2010), } \\
\text { Alexa Internet } \\
\text { (\$250M, 1999), } \\
\text { Havest.AI }(\$ 20 \mathrm{M} \text {, } \\
\text { 2017), Ring } \\
(\$ 890 \mathrm{M}, 2018) \text {, } \\
\text { PillPack (\$750M, } \\
\text { 2018) }\end{array}$ \\
\hline Apple & $\$ 258.5 B$ & $\begin{array}{l}\text { Eletrônicos, } \\
\text { Hardware, } \\
\text { Dispositivos móveis, } \\
\text { Software }\end{array}$ & 20.780 & $\begin{array}{l}\text { FileMaker } \\
\text { (customização de } \\
\text { apps), Braeburn } \\
\text { Capital (gestão de } \\
\text { ativos), AC Wellness } \\
\text { (grupo de saúde) }\end{array}$ & $\begin{array}{l}108 \\
- \\
\text { Beast Electronics } \\
(\$ 3 \mathrm{~B}, 2014), \\
\text { Dialog } \\
\text { Semiconductor } \\
(\$ 600 \mathrm{M}, 2018), \\
\text { Anobit }(\$ 500 \mathrm{M} \text {, } \\
2011), \text { NeXT } \\
(\$ 400 \mathrm{M}, 1997), \\
\text { Shazam }(\$ 400 \mathrm{M} \text {, } \\
2018), \text { PrimeSense } \\
(\$ 360 \mathrm{M}, 2013), \\
\text { AuthenTec } \\
(\$ 350 \mathrm{M}, 2012)\end{array}$ \\
\hline Microsoft & $\$ 122.2 \mathrm{~B}$ & $\begin{array}{l}\text { Inteligência artificial, } \\
\text { computação em } \\
\text { nuvem, eletrônicos, } \\
\text { ferramentas de } \\
\text { desenvolvimento, } \\
\text { software, sistemas } \\
\text { operacionais }\end{array}$ & 35.995 & $\begin{array}{l}\text { Jellyfish (plataforma } \\
\text { de compras), } \\
\text { Visual Studio } \\
\text { (desenvolvimento), } \\
\text { Xamarin (construção } \\
\text { de apps), Vexcel } \\
\text { (serviços), } \\
\text { SoftArtisans } \\
\text { (insights de dados), } \\
\text { Opalis software } \\
\text { (automação para TI), } \\
\text { Skype (plataforma } \\
\text { de comunicação } \\
\text { VoIP) }\end{array}$ & $\begin{array}{l}220 \\
- \\
\text { LinkedIn (\$2,6B, } \\
\text { 2016), Skype } \\
(\$ 8,5 \mathrm{~B}, 2011), \\
\text { GitHub }(\$ 7,5 \mathrm{~B}, \\
\text { 2018), Nokia } \\
\text { (\$7,2B, 2013), } \\
\text { Mojang }(\$ 2,5 \mathrm{~B}, \\
\text { 2014), Visio } \\
\text { Corporation } \\
\text { (\$1,3B, 2000), } \\
\text { Hotmail }(\$ 500 \mathrm{M}, \\
\text { 1997), Yammer } \\
(\$ 1,2 \mathrm{~B}, 2012)\end{array}$ \\
\hline
\end{tabular}

Fonte: Elaborado com base em dados do CrunchBase (2019). 
Conforme argumento de Daniel Crane (2018), desde o julgamento do caso Reiter v Sonotone Corporation pela Suprema Corte em 1979, tornou-se lugar-comum afirmar que o Sherman Act (a legislação pioneira em direito antitruste nos Estados Unidos) foi construído para promover o "bem-estar do consumidor". Em The Antitrust Paradox, Robert Bork (1978) cravou essa interpretação hoje dominante e definiu o bem-estar do consumidor simplesmente como a situação na qual se evitam "reduções de output" que poderiam levar a situações de perdas (deadweight losses). Essas situações seriam mais bem quantificadas por efeitos de preços, podendo incluir componentes adicionais como escolha, variedade e inovação. Os modelos de análise centrados em preço são, até hoje, os dominantes na discussão antitruste, garantindo uma posição de domínio ao ferramental analítico construído pela Escola de Chicago desde Bork (Wu, 2018).

No entanto, vários juristas do direito antitruste mostram que essa moldura teórica é incapaz de solucionar os problemas atuais das plataformas de múltiplos lados e de "data-driven markets" com histórico de concentração (Ezrachi; Stucke, 2016; Wu, 2018). Trata-se de problema metodológico altamente relevante e que tem sido amplamente discutido por especialistas e por autoridades de direito concorrencial do mundo todo (Crane, 2018; Wu, 2018).

Há um grande debate sobre a viabilidade de inclusão de finalidades políticas e sociais como integrantes de análise concorrencial. Também há uma forte polarização entre os chamados "neobrandeisianos", que defendem a relação direta entre antitruste e democracia (Waller, 2019) e a utilização de proxies de performance ligadas a estrutura de mercado (market structure) e tamanho (firm size), e os seus críticos, que advogam por abordagens "pós-Chicago", porém centradas em precificação predatória, tying e práticas excludentes (Crane, 2018).

Ao lado da reorganização do direito antitruste em um viés de intervenção estrutural, que se tornou lema da campanha da senadora norte-americana democrata Elizabeth Warren, pré-candidata presidencial (Break Up Big Tech), um segundo eixo de reinvenção do direito antitruste se encontra na atuação repressiva, quando as autoridades de defesa da concorrência encontram práticas unilaterais desleais e lesivas à ordem econômica. ${ }^{12}$

Esse segundo eixo, que difere completamente da atuação preventiva, é o que tem sido o foco principal de atuação da Comissária Europeia de Concorrência, Margrethe Verstager, em casos emblemáticos como o Google-Android, julgado em julho de 2018. ${ }^{13}$ No caso Google-Android, a Comissária Europeia identificou três tipos de restrições que a Google impôs às manufaturas de operadoras de redes, para garantir que os dados trafegassem para o Google Search e os servidores da Google. Primeiro, a Google exigiu que produtores de smartphones pré-instalassem buscadores e o app Google Search em aparelhos rodando no sistema operacional Android (de propriedade da Google). Era obrigatório aos fabricantes de celular pré-instalar o Google Search se eles tivessem interesse em 
vender dispositivos na Google App Store. Segundo, a Google pagou fabricantes e operadores de rede para garantir que somente o Google Search tivesse pré-instalado, diminuindo a capacidade competitiva de competidores como Bing e DuckDuckGo. Terceiro, conforme a Comissária Europeia, a Google obstruiu o desenvolvimento de sistemas operacionais de telefonia móvel competitivos, utilizando o Android como "veículo para sedimentar o domínio de seus próprio mecanismo de busca".

O caso Android é emblemático dessa tendência de "APIzação" (Villani, 2018) e arranjos contratuais que expandem a coleta de dados pessoais e colocam em xeque a questão do bem-estar do consumidor, desde que o conceito seja ressignificado $(\mathrm{Wu}, 2018)$. Além do debate sobre a perda de oportunidade de se beneficiar dos efeitos da competição - o que diminuiria o "bem estar do consumidor" -, o coração do caso está na relação entre essa APIzação e o exercício "de forma abusiva" de posição dominante, nos termos do art. 36 da Lei n.12.529/2011 (Lei Brasileira de Defesa da Concorrência). ${ }^{14}$

Por fim, há uma grande aposta que a General Data Protection Regulation e a Lei Geral de Proteção de Dados Pessoais (Lei n.13.709/2018) tragam efeitos concretos para o debate concorrencial. Primeiro, porque entre os novos "direitos digitais" garantidos pelas leis de proteção de dados pessoais está o direito à portabilidade de dados pessoais (presente no rol do art. 18, Lei n.13.709/2018).

Com o pleno exercício desse direito, espera-se que políticas como a de Open Banking criada pelo Banco Central do Brasil possam fomentar a circulação de dados pessoais desde que exista o consentimento e o pedido por parte do titular dos dados, fazendo que grandes instituições financeiras sejam obrigadas a garantir acesso a competidores (FinTechs), estimulando uma espécie de desagregação (unbundling) dos serviços financeiros hoje unificados. No coração desse debate estará a questão da padronização da portabilidade de dados e, também, as medidas de segurança necessárias para regulação do modo como se dará o acesso pelo competidor, bem como a segurança necessária para o transporte desses dados em atendimento ao princípio da segurança previsto no art. 6 da Lei Geral de Proteção de Dados Pessoais.

Segundo, pois existe uma tendência de algumas autoridade concorrenciais, como a Autoridade de Defesa da Concorrência da Alemanha (Bundeskartella$m t$ ), de construir precedentes de práticas unilaterais abusivas em razão da coleta massiva de dados pessoais sem a garantia dos direitos básicos dos titulares e os princípios de proteção de dados pessoais, como a base legal para tratamento e o princípio de finalidade e adequação. O caso limite dessa tendência é o construído pelo Bundeskartellamt em face do Facebook em fevereiro de 2019. A Autoridade decidiu que o Facebook não pode obter o consentimento "no atacado", por meio de uma única política, permitindo que metadados sejam amplamente coletados no Instagram, WhatsApp e sites de terceiros que possuem cookies de transmissão de dados para servidores Facebook. Conforme argumentado por 
Andreas Mundt, presidente da Bundeskartellamt, "a combinação de fontes de dados contribuiu substantivamente para o fato de o Facebook ter conseguido construir uma base de dados única para cada usuário e, assim, ter ganhado poder de mercado. No futuro, consumidores podem evitar que o Facebook colete e use seus dados de forma irrestrita" (Bundeskartellamt, 2019).

É evidente que essa aproximação não estará isenta de fricções no campo concorrencial (Krein, 2018; Wu, 2018; Crane, 2018). Sem dúvidas, surgirão argumentos sobre a inaplicabilidade do ferramental antitruste para lidar com esses casos, e argumentos de que as violações dos direitos à proteção de dados pessoais devem ser lidadas dentro do escopo específico de atuação das Autoridades Nacionais de Proteção de Dados Pessoais.

Esses casos, no entanto, sugerem uma aproximação entre o campo de proteção de dados pessoais e o campo da defesa da concorrência (Linskey, 2018), que se desenvolveram por meio de comunidades epistêmicas distintas e estruturas regulatórias que não se comunicavam claramente até então (Abramovay, 2018; Quintarelli, 2019, p.271-82). Com a entrada em vigor da Lei Geral de Proteção de Dados Pessoais em agosto de 2020 no Brasil, podem-se esperar movimentos semelhantes no Conselho Administrativo de Defesa Econômica (Cade) e disputas intensas sobre o que é de atribuição do Cade, o que é atribuição da Secretaria Nacional do Consumidor (responsável pela aplicação do Código de Defesa do Consumidor) e o que é de atribuição da futura Autoridade Nacional de Proteção de Dados Pessoais. ${ }^{15}$

Está cada vez mais claro que a "concorrência não está a um clique" e que nem todas as empresas podem ser Google (Mangabeira Unger, 2019). As discussões sobre "capitalismo de vigilância" (Zuboff, 2019) e as análises sobre comodificação do cotidiano por meio de sensores e metadados (Quitarelli, 2019) podem iluminar a discussão crítica sobre barreiras de entrada e domínio de mercado relevante de serviços. Em linhas gerais, como corretamente notado por Coutinho \& Kira (2018), o desenvolvimento avançado de plataformas digitais e a intensa coleta de dados pessoais representam novas fronteiras para a teoria clássica do antitruste, seja no vetor de controle de atos de concentração, seja na repressão a condutas anticompetitivas.

\section{Conclusão}

Existe um vínculo orgânico entre os vícios digitais expostos na primeira parte deste trabalho e os ataques contra a concorrência analisados a seguir. Nada exprime melhor essa ligação que o lema da Cambridge Analytica, a empresa que atuou na campanha vitoriosa de Donald Trump, sobre a base de informações recolhidas a partir de um questionário aplicado por meio do Facebook: "data drives all we do" (os dados determinam tudo o que fazemos).

A frase traz uma ambiguidade decisiva: os dados determinam tudo o que a economia da atenção faz, ou seja, a extração de dados incorpora-se aos objetos que compõem a vida cotidiana e ao mesmo tempo, o uso dos dados por parte 
das empresas que os detêm é capaz de exercer imensa influência sobre o que nós, cidadãos e consumidores, fazemos. Essa influência foi apresentada aqui tanto em sua capacidade de reter nossa atenção nos dispositivos digitais como nas consequências da economia da atenção sobre um dos pilares básicos da economia moderna: a concorrência.

Mas é evidente, como mostraram as ações da própria Cambridge Analytica, que a coleta, a armazenagem e a análise dos dados do cidadão abrem caminho também à interferência em sua vida cívica. $\mathrm{O}$ envio de mensagens massivas, mas personalizadas está dando lugar ao que Zeynep Tufecki (2018), professora da Universidade de Notre Dame, vem chamando de esfera pública fantasma: informações são enviadas de forma cuidadosamente selecionada a partir das informações reveladoras da personalidade e das inclinações de quem as recebe. Mas o envio é individualizado e chega às pessoas não pelo rádio, pela TV, pelo jornal ou em praça pública, e sim pela tela de seus smartphones. Isso inibe e distorce o debate aberto daquilo que se recebe e induz as pessoas a se confinarem em bolhas de redundância. Da mesma forma que ameaça a concorrência, o modelo de negócio dos gigantes digitais também favorece a formação de um ambiente político e cultural em que os cidadãos são afastados de horizontes diferentes daqueles em que já vivem. Como mostra Cass Sunstein (2018) não poderia haver ambiente mais favorável à polarização política e cultural.

O que está em jogo na vigilância sistemática, que se tornou o cerne da inovação tecnológica contemporânea, não são nossos segredos: é, antes de tudo, nossa autonomia, o controle de cada indivíduo sobre sua própria vida, a definição da identidade de cada um de nós e aquilo que o relator das Nações Unidas sobre o Direito à Privacidade (Humans Rights Council, 2019) chamou de nossa “autodeterminação”. É por isso que o Grupo de Assessoria Ética da Autoridade Europeia de Proteção de Dados insiste que "os seres humanos não são idênticos aos seus dados apesar da crescente precisão com a qual os seres humanos podem ser digitalmente modelados, suas qualidades e propriedades catalogadas, seus padrões sistematizados e seus comportamentos previstos" (Ethics Advisory Groups EDPS, 2018).

A legitimidade social das atividades dos gigantes digitais está sendo contestada de forma crescente nos Estados Unidos e na Europa. As legislações de proteção de dados pessoais aprovadas já em mais de 120 países são um passo importante para limitar o poder das empresas que hoje lideram o processo de extração, armazenamento e análise de nossos dados. Mas a amplitude e a profundidade da coleta de informações e sua presença nos mais triviais objetos da vida cotidiana exigem que seja colocada a pergunta ética decisiva: dados para quê e para quem?

Essas perguntas vêm sendo respondidas não só por esforços legislativos, mas por movimentos sociais e organizações de especialistas que procuram uma arquitetura que permita recuperar a internet como o mais importante bem pú- 
blico até hoje criado pela inteligência humana e não como o instrumento distópico da vigilância sistemática. É certamente uma das mais fascinantes e promissoras agendas de pesquisa e de ação cívica do mundo contemporâneo.

\section{Notas}

1 Uma arquitetura jurídica dá sustentação a esse sistema. De um lado, há os termos de uso que funcionam como contrato que garante o consentimento do usuário para que os dados sejam coletados, processados e compartilhados com terceiros. De outro lado, há contratos de licenciamento de software para que o SDK seja transferido entre empresa desenvolvedora e "empresas parceiras". É questionável, no entanto, o quão livre e informado é o consentimento dessas pessoas ao concordarem com esses termos de uso, pois há problemas agudos de assimetria de informação (Jin, 2018).

2 No Brasil, a recém-aprovada Lei Geral de Proteção de Dados Pessoais (Lei n.13. $709 / 2018$ ), que entra em vigor em agosto de 2020, traz como fundamento da proteção de dados pessoais a autodeterminação informativa (art. $2^{\circ}$, II) e a dignidade (art. $\left.2^{\circ}, \mathrm{VII}\right)$. Sobre o conceito de autodeterminação informativa, ver Mendes (2018).

3 Utilizamos as expressões privacidade e proteção de dados pessoais em conjunto para fins de exposição simplificada, porém reconhecemos o amplo debate sobre a diferenciação entre os dois conceitos e a autonomização da proteção de dados pessoais no campo jurídico, tal como argumentado por Stefano Rodotà (2018). A Carta de Direitos Fundamentais de 2000 da União Europeia é um exemplo claro de autonomização da proteção de dados pessoais.

4 Disponível em: <https://www.aap.org/en-us/about-the-aap/aap-press-room/Pages/American-Academy-of-Pediatrics-Announces-New-Recommendations-for-Childrens-Media-Use.aspx>.

5 Disponível em: <https://www.bankmycell.com/blog/smartphone-addiction/\#chapter0>, Acesso em: 15 jun. 2019.

6 Disponível em: <https://www.who.int/features/qa/gaming-disorder/en/>.

7 Em nosso entendimento, esse raciocínio está totalmente alinhado com o "princípio da prevenção" do art. $6^{\circ}$ da Lei Geral de Proteção de Dados Pessoais, que exige a "adoção de medidas para prevenir a ocorrência de danos em virtude do tratamento de dados pessoais". A grande questão é a clareza sobre o tipo de dano existente e as formas de remediá-lo.

8 Apesar de não ser nosso objetivo aprofundar a análise da LGPD, é fundamental entender o impacto do capítulo de tratamento de dados pessoais de crianças e adolescentes, em especial a regra que impede o condicionamento da participação de crianças e adolescentes em jogos, aplicações de internet ou outras atividades mediante fornecimento de informações pessoais (art. 14).

9 Somente nos últimos dois anos, segundo levantamento da Esalq/USP, surgiram mais de 200 empresas de AgriTech, muitas delas dedicadas a geotagging de maquinário do campo, comunicação máquina-a-máquina (M2M) e "smart farming", fazendo que o campo esteja integrado com sensores, redes de comunicação e infraestrutura de analytics. Além da área rural, o Plano Nacional prevê potencialidades na área da saúde e de projetos urbanos (smart cities). 
10 Deverão ser submetidos ao Cade para apreciação os atos de concentração que (a) pelo menos um dos grupos envolvidos na operação tenha faturamento bruto anual ou volume de negócios total no país, segundo último balanço, equivalente ou superior a RS 750 milhões e (b) pelo menos outro grupo envolvido na operação tenha registrado faturamento bruto anual ou volume de negócios total no país equivalente ou superior a R\$ 75 milhões. No Brasil, por exemplo, pela regra de faturamento, o WhatsApp não precisou ser analisado.

11 Como argumentado por Julia Krein (2018), na dinâmica de negócios de mercados de dois ou múltiplos lados, os usuários não incorrem em custos monetários para utilizar serviços (o Instagram é "gratuito"). Isso faz que a transação seja descrita como gratuita e, por esse motivo, "excluída da análise antitruste", uma vez que, "sem preços, não há mercados e, portanto, não pode haver prejuízo à concorrência” (Krein, 2018, p.203).

12 Entre as várias condutas de infração à ordem econômica na Lei do Cade está aumentar arbitrariamente lucros, exercer de forma abusiva posição dominante, promover adoção de conduta comercial uniforma ou concertada entre concorrentes, limitar ou impedir o acesso de novas empresas ao mercado, criar dificuldades à constituição ou desenvolvimento de empresa concorrente, impedir o acesso de concorrente às fontes de insumo, matérias primas, equipamentos ou tecnologia, exigir ou conceder exclusividade para divulgação de publicidade, entre outros previstos no art. 36 da Lei n.12.529/2011.

13 Por questões de escopo, não analisaremos o caso Google-Shopping. Para uma análise crítica, ver Daly (2017).

14 No Brasil, presume-se posição dominante sempre que uma empresa ou grupo de empresas for capaz de alterar unilateral ou coordenadamente as condições de mercado ou quando controlar $20 \%$ ou mais do mercado relevante, podendo esse percentual ser alterado pelo Cade para setores específicos da economia.

15 Nos Estados Unidos, os argumentos mais ousados e bem articulados sobre a reorientação do antitruste em um viés de intervenção estrutural em razão do poder de mercado das empresas de tecnologia são os mobilizados por Khan (2017) e Wu (2018). No entanto, mesmo nos movimentos sociais, há os que defendem que a solução seria uma reestruturação da FTC em um viés de defesa do consumidor. Kimelman, Feld e Rossi (2018) admitem problemas centrais de lesões coletivas relacionadas à coleta massiva de dados pessoais, mas afirmam que o direcionamento do antitruste para a privacidade (i) seria desgastante em termos de energia e política e falta de clareza conceitual, (ii) poderia gerar consequências não previstas, como a fragmentação de um “ofensor” em vários "privacy offender competitors", e (iii) seria incapaz de olhar a figura mais ampla de desproteção de dados pessoais, que deveria ser analisada por uma moldura jurídica própria, como a General Data Protection Regulation ou a Lei Geral de Proteção de Dados Pessoais (Lei n.13.790/2018). É de se esperar um impacto dessa discussão no Brasil.

\section{Referências}

ABRAMOVAY, R. Aos dados cidadãos. 451 A Revista dos Livros, 2018. Disponível em: $<$ http://ricardoabramovay.com/aos-dados-cidadaos/>. 
ALTER, A. Irresistible: The rise of addictive technology and the business of keeping us hooked. New York: Penguin, 2017.

ARTHUR, B. Where is technology taking the economy. McKinsey Quarterly, out. 2017. Disponível em: <https://www.mckinsey.com/business-functions/mckinsey-analytics/ our-insights/where-is-technology-taking-the-economy>. Acesso em: 15 jun. 2019.

BAGNOLI, V. The Big Data Revelant Market. Concorrenza \& Mercato, v.23, 2016.

BALKIN, J. M. Information fiduciaries and the first amendment. UCDL Rev., v.49, p.1183, 2015.

The Three Laws of Robotics in the Age of Big Data. Obio St. LJ, v.78, p.1217, 2017.

BENKLER, Y. The Wealth of Networks. How Social Production Transforms Marketys and Freedom. New Haven: Yale University Press, 2006.

BORGMANN, A. Technology and the character of contemporary life: A philosophical inquiry. Chicago: University of Chicago Press, 1987.

BORK, R. The Antitrust Paradox. New York: Basic Books, 1978.

BUNDESKARTELLAMT. Bundeskartellamt probibits Facebook from combining user data from different sources, Press Release, 07/02/2019. Disponível em: <https://www.bundeskartellamt.de/SharedDocs/Meldung/EN/Pressemitteilungen/2019/07_02_2019_ Facebook.html>. Acesso em: 25 jun. 2019.

CHOMSKY, N. The case against BF Skinner. The New York Review of Books, v.17, n.11, p.18-24, 1971.

COUTINHO, D.; KIRA, B. Vinho novo em garrafas velhas, Jota, 2 jul. 2018.

CRANE, D. A. Four Questions for the Neo-Brandeisians. Antitrust Chronicle, v. 2, 2018.

CRUNCHBASE, CrunchBase Data Base, 2019. Disponível em: <https://www.crunchbase.com/>. Acesso em: 25 jun. 2019.

CURTIS, B. Foucault on governmentality and population: The impossible discovery. Canadian Journal of Sociology, v.27, n.4, p.505-35, 2002.

DALY, A. Beyond Hipster Antitrust: A Critical Perspective on the European Commission's Google Decision. Eur. Competition \& Reg. L. Rev., v.1, p.188, 2017.

ENJOLRAS, F. Gare à ces 'algorithmes qui pourraient finir par nous connaître mieux que nous nous connaissons nous-mêmes'.. Le Monde, 26.12. 2018. Disponível em : <https://www.lemonde.fr/sciences/article/2017/12/26/gare-a-ces-algorithmes-qui-nous-connaissent-mieux-que-nous-memes_5234390_1650684.html>. Acesso em: 15 jun. 2019.

ETHICS ADVISORY GROUP EDPS. Towards a Digital Ethics, 2018. Disponível em: <https://edps.europa.eu/sites/edp/files/publication/18-01-25_eag_report_en. pdf>. Aesso em: 15 jun. 2019.

EZRACHI, A.; STUCKE, M. E. Virtual competition. Oxford: Oxford University Press, 2016.

FIDELIS, A. Data-driven mergers: a call for further integration of dynamics effects into competition, Revista de Defesa da Concorrência, v.5, n.2, p.207, 2017. 
FREUD, S. L'Inquiétante étrangeté, 1919. Disponível em: <http://palimpsestes.fr/ textes_philo/freud/inquietante-etrangete.pdf>. Acesso em: 15 jun. 2019.

FOGG, B. J. Persuasive Computers: Perspectives and Research Directions. CHI 98. Proceedings of the SIGCHI Conference on Human Factos in Computing Systems, 1998, p.225-232. Disponível em: <https://dl.acm.org/citation.cfm?id=274677>.

FLORIDI, L. The Ethics of Information. Oxford: Oxford University Press, 2013.

. Three problems with group privacy and their solutions. In: Group privacy: new challenges of data technologies. Philosophical Studies. New York: Springer, 2016.

FLORIDI, L.; TADDEO, M. What is data ethics? Phil. Trans. R. Soc. A 374: 20160360, 2018. Disponível em: <http://dx.doi.org/10.1098/rsta.2016.0360>.

FRISCHMANN, B.; SELINGER, E. Re-engineering humanity. Cambridge University Press, 2018.

FTC, Statement of Federal Trade Commission concerning Google/DoubleClick, FTC File. 071-0170, Washington: FTC, 2007.

HAN, B.-C. No Enxame: perspectivas do digital. Rio de Janeiro: Vozes, 2018.

HANVEY, B. Your Car Knows When You Gain Weight. The New York Times, 17.4.2019.

Disponível em: <https://www.nytimes.com/2019/05/20/opinion/car-repair-data-privacy.html>. Acesso em: 15 jun. 2019.

HARTZOG, W. Privacy's Blueprint. The Battle to Control the Design of New Technologies. Cambridge: Harvard University Press, 2018.

HARTZOG, W.; SELINGER, E. Why You Can No Longer Get Lost in the Crowd. The New York Times, The Privacy Project, 17.4.2019.

HAYEK, F. The Use of Knowledge in Society. American Economic Review, v.XXXV, n.4, p.519-30, 1945.

HILDEBRANDT, M. Legal and technological normativity: more (and less) than twin sisters. Techné: Research in Philosophy and Technology, v.12, n.3, p.169-83, 2008.

HOWARD, J. Kids under 9 spend more than 2 hours a day on screens, report shows. CNN, 2017. Disponível em: <https://edition.cnn.com/2017/10/19/health/children-smartphone-tablet-use-report/index.html>. Acesso em: 15 jun. 2019.

HUMAN RIGHTS COUNCIL. Report of the Special Rapporteur on the right to privacy, 2019. Disponível em: <https://rm.coe.int/40th-hrc-session-report-of-the-special-rapporteur-on-the-right-to-priv/1680933f08>. Acesso em: 15 jun. 2019.

JIN, G. Z. Artificial intelligence and consumer privacy. National Bureau of Economic Research, 2018.

KHAN, L. M. Amazon's Antitrust Paradox. The Yale Law Journal, v.126, n.3, Jan. 2017.

KHAN, L.; POZEN, D. A Skeptical View of Information Fiduciaries. Harvard Law Review, v.133, 2019.

KIMMELMAN, G.; FELD, H.; ROSSI, A. The limits of antitrust in privacy protection, International Data Privacy Law, v.8, n.3, p.270-6, Aug. 2018.

KINGE, J.; LOUISE L.; WONG, S. Huawei looks to self-driving cars in bid to broaden AI focus. Financial Times, 21.6.2019. Disponível em: <https://www.ft.com/ 
content/6ee22ee4-8ce2-11e9-a24d-b42f64leca37? emailId=5d00c76059f5900004 c7e88e\&segmentId=3934ec55-f741-7a04-feb0-1ddf01985dc2>. Acesso em: 15 jun. 2019.

KREIN, J. Novos trustes na era digital: efeitos anticompetitivos do uso de dados pessoais pelo Facebook. Revista de Defesa da Concorrência, v.6, n.1, p.211, 2018.

KUCHLER, J. Why quitting smartphones is the new tuitting smoking. Financial Times, 24.1.2018. Disponível em: <https://www.ft.com/content/4f82a008-009611e8-9650-9c0ad2d7c5b5>. Acesso em: 15 jun. 2019.

KWET, M. In stores, secret surveilance tracks your every move. New York Times, The Privacy Project, 14.6.2019. Disponível em: <https://www.nytimes. com/interactive/2019/06/14/opinion/bluetooth-wireless-tracking-privacy. html action $=$ click\&module $=$ privacy $\% 20$ footer $\% 20$ recirc\% 20 module \&pgtype $=$ Article $>$.

LESSIG, L. Code and other Laws of Cyberspace. New York: s. n., 1999.

LYNSKEY, O. At the crossroads of data protection and competition law: time to take stock. International Data Privacy Law, v.8, n.3, p.179, 2018.

MANGABEIRA UNGER, R. A economia do conbecimento. São Paulo: Autonomia Literária, 2019.

MCNAMEE, R. A Brief History of How Your Privacy Was Stolen. The New York Times, 3.6.2019. Disponível em: <https://www.nytimes.com/2019/06/03/opinion/ google-facebook-data-privacy.html>. Acesso em: 15 jun. 2019.

MENDES, L. S. F. Habeas data e autodeterminação informativa. Revista Brasileira de Direitos Fundamentais \& Justiça, v.12, n.39, p.185-216, 2018.

METZ, C. Turing Award Won by 3 Pioneers in Artificial Intelligence. The New York Times. 27.3.2019. Disponível em: <https://www.nytimes.com/2019/03/27/technology/turing-award-ai.html?module=inline > . Acesso em: 15 jun. 2019.

MOROZOV, E. Big Tech: a ascensão dos dados e a morte da política. São Paulo: Ubu, 2018.

MORRIS, S. Facial Recognition tech: watchdog calls for code to regulate police use. The Guardian, 23.5.2019. Disponível em: <https://www.theguardian.com/technology/2019/may/23/facial-recognition-cameras-watchdog-code-regulate-police $>$. Acesso em: 15 jun. 2019.

OU, E. Treat Facebook Like Big Tobacco. Bloomberg, Technology \& Ideas, 17.5.2019. Disponível em: <https://www.bloomberg.com/opinion/articles/2019-05-17/regulate-facebook-like-big-tobacco-not-like-a-phone-company>.

QUINTARELLI, S. Instruções para um futuro imaterial. São Paulo: Elefante, 2019.

RODOTÀ, S. Vivere la Democrazia. Roma: Laterza, 2018.

SCHULSON, M. User behaviour, Aeon Magazine, 2018. Disponível em: https:// aeon.co/essays/if-the-internet-is-addictive-why-don-t-we-regulate-it. Acesso em: 25 jun. 2019.

SECRETARIA ESPECIAL DE COMUNICAÇÃO SOCIAL DA PRESIDÊNCIA DA REPÚBLICA. Pesquisa Brasileira de Mídia. Hábitos de Consumo de Mídia pela População Brasileira. Brasília, 2016. 
SHAPIRO, R.; ANEJA, S. Who Owns Americans'Personal Information and What Is It Worth? Future Majority, 2019. Disponível em: <https://assets.futuremajority.org/ uploads/report-for-future-majority-on-the-value-of-people-s-personal-data-shapiro-aneja-march-8-2019.pdf>. Acesso em: 15 jun. 2019.

SKINNER, B. F. Para além da liberdade e da dignidade. Lisboa: Edições 70, 2000.

STIGLER, G. J. The economics of information. Journal of Political Economy, v.69, n.3, p.213-25, 1961.

STUCKE, M. Should We Be Concerned about Data-Opolies? Georgetown Law Technology Review, 275, 2018.

SUNSTEIN, C. R. \# Republic: Divided democracy in the age of social media. Princeton University Press, 2018.

TUFECKI, Z. It's the (democracy-poisoning) golden age of free speech. Wired, 16.1.2018. Disponível em: <https://www.wired.com/story/free-speech-issue-tech-turmoil-new-censorship/>. Acesso em: 15 jun. 2019.

TUFEKCI, Z. Think You're Discreet Online? Thing Again. The New York Times. Privacy Project, 21.4.2019. Disponível em: <https://www.nytimes.com/2019/04/21/ opinion/computational-inference.html>. Acesso em: 15 jun. 2019.

VALENTION-DEVRIES, J.; SINGER, N.; KROLIK, A. Your Apps Know Where You Were Last Night, and They're Not Keeping It Secret. The New York Times, 10.12.2018. Disponível em: <https://www.nytimes.com/interactive/2018/12/10/business/location-data-privacy-apps.html>. Acesso em: 15 jun. 2019.

VILLANI, C. For a Meaningful Artificial Intelligence. Towards a French and European Strategy. A parliamentary mission from 8th Septeumber 2017 to 8th March 2018. Disponível em: <https://www.aiforhumanity.fr/pdfs/MissionVillani_Report_ENG-VF. pdf>. Acesso em: 15 jun. 2019.

WALLER, S. W. Antitrust and Democracy. Florida State University Law Review, v.45, 2019.

WEISS, M. Sociedade sensoriada: a sociedade da transformação digital. Estudos Avançados, v.33, n.95, p.203-14, jan./abril 2019.

WU, T. The Attention Merchants: The Epic Scramble To Get Inside Our Heads. London: Atlantic Books, 2016.

The Curse of Bigness. Columbia Global Reports, 2018.

ZUBOFF, S. The Age of Surveillance Capitalism: The Fight for a Human Future at the New Frontier of Power. New York. Public Affairs, 2019.

ZUCKERBERG, M. Um olhar sobre o modelo de negócios do Facebook. Fotha de S.Paulo, 24.1.2019. Disponível em: <https://wwwl.folha.uol.com.br/opiniao/2019/01/um-olhar-sobre-o-modelo-de-negocio-do-facebook.shtml>.

ZUCKERMAN, E. Facebook Only Cares About Facebook. The Atlantic, 27.1.2018. Disponível em: <https://www.theatlantic.com/technology/archive/2018/01/facebook-doesnt-care/551684/>. Acesso em: 14 jun. 2019. 
RESUMO - O presente ensaio identifica e discute dois problemas emergentes relacionados aos poderes das grandes empresas de tecnologia que atuam na camada de aplicações de internet e que se dedicam, direta ou indiretamente, à exploração de dados pessoais. $\mathrm{O}$ primeiro é o modo como dispositivos e funcionalidades são construídos para gerar adição e maximizar o tempo de atenção dos usuários. O segundo é o crescimento massivo de algumas poucas empresas nesses novos mercados e a reinvenção do direito concorrencial, em sua vertente repressiva e preventiva, a partir de uma aproximação com o direito à proteção de dados pessoais.

PALAVRAS-CHAVE: Economia digital, Concorrência, Vícios digitais, Proteção de dados pessoais.

ABSTRACT - This paper identifies and discusses two emerging issues related to the power of large technology companies that provide Internet apps and are engaged in the exploitation of personal data. The first is how devices and features are developed to generate addiction and minimize the attention span of users. The second is the massive growth of a small number of companies in these new markets and the reinvention of competitive business laws, and their repressive and preventive dimension, analyzed from the viewpoint of private data protection laws.

KEYWORDS: Digital economy, Competition, Digital addiction, Private data protection.

Rafael A. F. Zanatta é doutorando pelo Instituto de Energia e Ambiente da Universidade de São Paulo (IEE/USP). @ - rafaelzanatta@usp.br /

https://orcid.org/0000-0001-9111-7594

Ricardo Abramovay é economista e professor da Faculdade de Economia, Administração e Contabilidade da Universidade de São Paulo. @ - abramov@usp.br / https://orcid.org/0000-0003-1836-5991

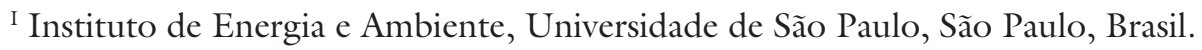

II Faculdade de Economia, Administração e Contabilidade, Universidade de São Paulo, São Paulo, Brasil.

Recebido em 17.6.2019 e aceito em 20.7.2019. 